\title{
Teoria e prática das finanças corporativas: novas evidências para o Brasil
}

\author{
Alberto Granzotto* \\ Augusto SARuba BaLdassari** \\ IGOR BERNARDI SONZA***
}

\begin{abstract}
RESUMO
O presente estudo buscou identificar quais as técnicas de análise financeiras são mais usuais nas empresas de capital aberto brasileiras. Para isso foi aplicado uma survey, tendo como instrumento um questionário composto por 17 construtos e 107 questões abertas e fechadas, no qual foram respondidas por meio de contato direto com os diretores financeiros das empresas negociadas na B3, seja por meio de telefone seja por endereços de e-mail, disponíveis na ficha cadastral na B3. Os principais resultados do artigo apontam que as "Opções reais" é a técnica mais utilizada pelos respondentes e o PayBack a menos utilizada. Este resultado demonstra que as empresas estão cada vez mais especializadas, deixando de usar técnicas simples. Outra questão importante a ser relatada, diz respeito à escala de prioridades quando as empresas precisam obter recursos, confirmando que a lógica do trade-off se sobrepõe a da pecking-order.
\end{abstract}

Palavras-chave: Finanças corporativas. Teoria. Prática.

\section{THEORY AND PRACTICE OF CORPORATE FINANCE: NEW EVIDENCE FOR BRAZIL}

\begin{abstract}
The present study sought to identify which financial analysis techniques are most common in Brazilian publicly traded companies. For this, a survey was applied, having as instrument a questionnaire composed of 17 constructs and 107 open and closed questions, through direct contact with the financial directors of the companies negotiated in B3, either by telephone or by e-mail addresses, available on the registration form on B3. The main results of the article indicate that the "Real Options" is the technique most used by the respondents and the least used PayBack. This result shows that companies are becoming more specialized, not using simple techniques. Another important issue to be addressed concerns the scale of priorities when companies need to obtain resources, confirming that the trade-off logic overlaps with pecking-order logic.
\end{abstract}

Keywords: Corporate finance. Theory. Practice

\footnotetext{
*UFSM. betorg@ymail.com .

** UFSM. augusto.sb21@gmail.com .

*** UFSM. igorsonza@gmail.com .
} 


\section{INTRODUÇÃo}

A análise de demonstrativos surgiu e se desenvolveu a partir do sistema bancário norte americano, dado que as instituições financeiras faziam o uso destes dados para analisar a possibilidade de empréstimos a terceiros. Desde então se desenvolveu cada vez mais técnicas de análise financeira, abrangendo todos os níveis das organizações.

Com o avanço constante da área financeira é necessário lapidar informações brutas vindas das demonstrações contábeis e financeiras, esses dados após passarem por uma transformação são de grande importância para projetar o futuro da empresa (BRAGA, 2008).

Segundo Graham e Harvey (2001), "grandes empresas dependem fortemente de técnicas de valor presente e o modelo de precificação de ativos de capital, enquanto as pequenas empresas são relativamente propensas a usar o critério de payback". Será que o mesmo se reflete para as finanças corporativas brasileiras? Este é um fato que se busca descobrir com o estudo, fazendo o uso da mesma Survey dos referidos autores.

Um número grande de empresas usa o risco da firma ao invés de risco do projeto na avaliação de novos investimentos. As empresas estão preocupadas com flexibilidade financeira e ratings de crédito na emissão de dívida, e lucro por diluição de ação e recente valorização do preço das ações quando da emissão de capital próprio (GRAHAM; HARVEY, 2001).

Sendo assim, uma pesquisa no Brasil, a fim de levantar dados históricos para o país, do mesmo modo como os autores citados fizeram em seu país, começaram a levantar hipóteses importantíssimas e muito estudadas até os dias de hoje, criando diversos parênteses a serem discutidos e melhor trabalhados. Esta pesquisa empírica nas finanças corporativas brasileiras, será de grande impacto para novos estudos nessa área, pois há poucos estudos sobre esse assunto no Brasil, fazendo assim necessário uma pesquisa com esse tema e assim aprimorar o conhecimento que temos do uso teórico da administração financeira e sua eficácia e eficiência na prática, a fim de promover melhores e maiores resultados.

O estudo busca replicar no Brasil a investigação empírica desenvolvida por Graham e Harvey (2001), no qual buscaram verificar quais as técnicas financeiras são utilizadas nas empresas de capital aberto. $\mathrm{O}$ uso de métodos financeiros nas rotinas administrativas foi testado, bem como a aplicação de teorias sobre custo de capital, orçamento de capital e estrutura de capital.

Devido a este contexto, o presente trabalho visa analisar a aplicação das teorias financeiras nas empresas de capital aberto brasileiras. A estrutura do presente artigo está dividida em 5 (cinco) seções, sendo a primeira parte introdutória, a segunda parte revisão bibliográfica, a terceira parte refere-se a metodologia e como foi a elaboração do questionário da survey. Já a quarta parte do trabalho discute os resultados da pesquisa e a quinta conclui.

\section{TEORIA E PRÁTICA EM FINANÇAS CORPORATIVAS}

Diversas pesquisas e estudos sobre teoria e prática das técnicas e métodos de análise financeira foram elaborados ao longo das últimas décadas e em diversos países, logo 
abaixo, no Quadro 1, há uma síntese de principais trabalhos desta área de pesquisa. Assim, pode-se ter um melhor parâmetro para comparação com os resultados desta pesquisa. Dessa forma, fez-se um apanhado dos artigos desde o ano de 2000 até o ano de 2014, em trabalhos já publicados. A seguir, foram descritos alguns trabalhos relacionados ao estudo, assim como os principais resultados encontrados.

Fillol et al. (2012) aplicaram uma survey de técnicas de orçamento de capital nos portos do Brasil e da Espanha a fim de gerar uma comparação entre eles. Um aspecto abordado pelos autores de grande relevância é a falta pesquisas relativas a orçamento de capital em empresas portuárias, sendo que a ineficiência nas distintas atividades de um porto pode afetar diretamente e indiretamente o processo de distribuição de mercadorias e assim a sociedade e a economia.

Ao elaborar um estudo em empresas do ramo alimentício que possuem seu capital aberto no Brasil, Oliveira et al. (2006) identificaram as estratégias e técnicas de financiamento do capital de giro adotadas pelas empresas, avaliando os perfis financeiros a partir de um modelo dinâmico de Fleuriet (método para a gestão operacional e dinâmica da empresa, dando ênfase maior à liquidez e à gestão dos fluxos de caixa operacionais). Os resultados mostram que existem certos padrões de financiamento mais conservadores como no setor cafeeiro e técnicas com padrões mais agressivos nos setores de carnes e laticínios, já no setor de grãos não se observou nenhum padrão a ser discutido.

Netto (2009) aplicou uma survey para 116 empresas Brasileiras de capital aberto e não-financeiras, com o intuito de desvendar quais são as técnicas de orçamento de capital mais usuais entre as empresas da amostra. Tendo como variável o tamanho da empresa, e aplicando regressões por MQO (Mínimos Quadrados Ordinários) identificou que a rentabilidade não se mostrou tão importante para as empresas e o endividamento a longo prazo é bem considerado, não sendo possível analisar uma técnica mais predominante dentre as discutidas e pesquisadas nas empresas.

Aplicando uma survey para 336 diretores financeiros nos EUA com o objetivo de comparar a teoria e prática nas áreas de Oferta Pública inicial, timing, seleção subscrição, cotação, sinalização e decisão de não abrir capital, Brau e Fawcett (2006) identificaram que a principal motivação para abrir capital é facilitar as aquisições. Em compensação, colocaram como principal problema a perda de controle das tomadas de decisão e da propriedade.

Chazi, Terra e Zanella (2009), nesta mesma linha, confrontaram a teoria e a prática de gestores financeiros do oriente médio, por meio de aplicação de uma survey com base nos estudos dos autores Graham e Harvey (2001) e Brounen et al (2004), utilizando estrutura de capital, orçamento de capital e governança corporativa como aspectos-chave.

Analisando 88 empresas no Canadá, Bennouna, Meredith e Marchant (2010) buscaram desvendar como e porque o IRR (Taxa interna de retorno) e o NPV (valor presente líquido) são os mais populares nos Fluxos de caixa descontado, quais são as práticas de orçamento de capital e também quais são as técnicas mais usuais em fluxo de caixa descontado. O resultado de sua pesquisa empírica foi de que $17 \%$ das empresas pesquisadas não fazem o uso de fluxo de caixa descontado e a maioria dessas empresas utiliza o valor pre- 
sente líquido (VPL) e a taxa interna de retorno (TIR) constantemente. Uma das surpresas da pesquisa foi que apenas $8 \%$ da amostra usam técnicas de opções reais.

Abdel-Kader e Luther (2006) buscam estabelecer quais são as técnicas de contabilidade utilizadas por indústrias do ramo de alimentos e bebidas britânicas, sua survey foi elaborada a partir de pesquisas anteriores e com entrevistas preliminares e aplicada no reino Unido para empresas do setor fabril. Em seus resultados foi percebido que muitas dessas empresas se utilizam de técnicas não financeiras como Balance Scorecard e a Planta ABC também conhecida como Curva ABC como critério para a tomada de decisões.

Buscando entender se as empresas holandesas utilizam técnicas teóricas mais sofisticadas e se utilizam na prática o orçamento de capital para lidar melhor com as incertezas na tomada de decisão de um investimento, Verbeeten (2006) aplicou uma survey elaborada através de estudos anteriores, e aplicada em 189 organizações. Nos seus resultados mostra que realmente estas organizações estão buscando técnicas mais sofisticadas no seu orçamento de capital, como ferramentas ou procedimentos assim como a técnica de Monte Carlo, simulações de investimentos, teoria dos jogos e opções reais.

Holmén et al. (2009) aplicaram uma survey na Suécia, a fim de desvendar e confrontar a teoria e a prática de orçamento de capital em empresas tipicamente suecas, delimitando quais são as técnicas utilizadas e se teoria está sendo posta em prática literalmente. Seus resultados foram intimidadores, pois técnicas populares como Valor Presente Líquido e Taxa Interna de Retorno, que em teoria são mais eficientes e eficazes no orçamento de capital para um investimento, muitas vezes são substituídos por técnicas como PayBack que, na sua teoria, incorrem um maior risco e uma credibilidade baixa.

Neste mesmo ínterim, Loewenstein e Willard (2006) realizaram uma pesquisa bibliográfica nos Estados Unidos, com a intenção de identificar e descrever como é o comportamento de um investidor contemporâneo, com base em estudos anteriores e modelos em livros, foi feita uma base teórica que foi confrontada com a prática em si. $\mathrm{O}$ estudo levou ao fato de que a ausência de oportunidade no período de arbitragem, medidas clássicas hoje vistas como antigas para a realidade, risco econômico, violações de preço único, entre outros aspectos que podem vir a interferir no comportamento do investidor e assim o guiando a tomar decisões precipitadas e de alto risco.Libby e Lindsay (2010) fizeram um levantamento para identificar quais as práticas de orçamento de capital que as empresas de grande e médio porte norte americanas vêm utilizando nos últimos anos. Concluíram que, as empresas utilizam as práticas orçamentárias com o objetivo de controle e são percebidas como valor agregado enquanto algumas empresas encontram problemas nas técnicas de orçamento, porém elas estão se atualizando e buscando novas técnicas para suprir esses problemas ao invés de abandonar de vez o seu uso.

Já Garmaise (2015) elaborou uma pesquisa qualitativa em confronto com a teoria e a prática de avaliação de riscos e controle de instituições financeiras, a pesquisa ocorreu por meio de observação em um banco de dados de um Banco em um período de 2004 a 2008, usando técnicas de descontinuidade de regressão. Nos seus resultados mostram que na teoria na prática há uma grande divergência, com apenas $25 \%$ de práticas e teorias sendo totalmente iguais. $\mathrm{O}$ estudo detectou que a falta de estudo sobre o cliente incorreu em uma dobra no risco de inadimplência. 


\begin{tabular}{|c|c|c|c|c|c|c|c|c|c|c|c|c|c|c|}
\hline so.t?no & n & 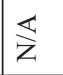 & 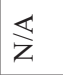 & $\overleftrightarrow{⿱ 乛}$ & 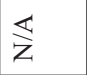 & $\frac{\vec{m}}{m}$ & 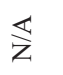 & 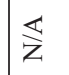 & 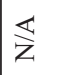 & 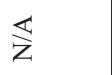 & 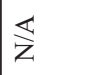 & $\vec{\sigma}$ & $\overleftrightarrow{\mathrm{z}}$ & \\
\hline овs!̨әр әр ә.ом..у & $\overleftrightarrow{z}$ & $\overleftrightarrow{\mathrm{z}}$ & $\vec{m}$ & $\overleftrightarrow{\breve{z}}$ & 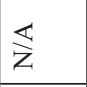 & 은 & $\overleftrightarrow{\breve{z}}$ & $\overleftrightarrow{\mathrm{z}}$ & $\overleftrightarrow{\mathrm{z}}$ & $\overleftrightarrow{\breve{z}}$ & $\overleftrightarrow{\breve{z}}$ & $\stackrel{\infty}{\sim}$ & $\tilde{\lambda}$ & \\
\hline 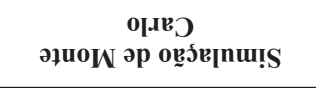 & $\overleftrightarrow{\mathrm{z}}$ & $\overleftrightarrow{z}$ & $\stackrel{n}{m}$ & $\overleftrightarrow{\breve{z}}$ & $\overleftrightarrow{\mathrm{z}}$ & $\overleftrightarrow{\text { z }}$ & $\overleftrightarrow{\breve{z}}$ & 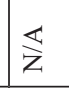 & $\overleftrightarrow{\breve{z}}$ & $\overleftrightarrow{\mathrm{z}}$ & $\overleftrightarrow{\measuredangle}$ & น & $\infty$ & \\
\hline 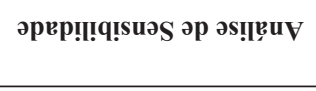 & $œ$ & $\frac{n}{n}$ & $\vec{\infty}$ & 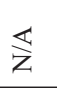 & $g$ & $\begin{array}{l}m \\
m \\
\infty \\
i\end{array}$ & 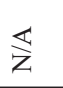 & 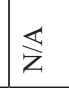 & $\overleftrightarrow{z}$ & $\begin{array}{l}\infty \\
\hat{\alpha}\end{array}$ & $\hat{i}$ & ते & $\tilde{\lambda}$ & \\
\hline 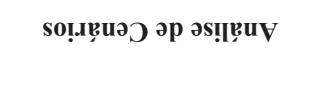 & $œ$ & $\overleftrightarrow{\mathrm{z}}$ & $\begin{array}{l}\infty \\
8 \\
8\end{array}$ & 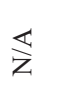 & 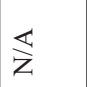 & i & 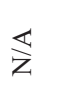 & $\overleftrightarrow{Z}$ & 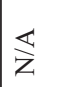 & $\begin{array}{c}m \\
\infty \\
\infty\end{array}$ & $\overleftrightarrow{\mathrm{Z}}$ & ले & $\begin{array}{l}m \\
\tilde{n} \\
n\end{array}$ & \\
\hline so.pno & $\approx$ & $\overleftrightarrow{z}$ & $\begin{array}{l}+ \\
\infty\end{array}$ & $\stackrel{+}{\infty}$ & $\overleftrightarrow{z}$ & $\vec{m}$ & $\approx$ & $\tilde{n}$ & $\overleftrightarrow{\mathrm{z}}$ & $\hat{\mathrm{I}}$ & $\overleftrightarrow{z}$ & $\overleftrightarrow{z}$ & $\overleftrightarrow{z}$ & \\
\hline 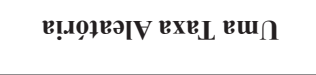 & 6 & $\overleftrightarrow{\nwarrow}$ & $\overleftrightarrow{\mathrm{z}}$ & $\underset{\mathrm{z}}{\overleftrightarrow{\mathrm{Z}}}$ & $\overleftrightarrow{\text { z }}$ & $\begin{array}{l}1 \\
\text { î } \\
\text { in }\end{array}$ & 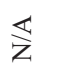 & 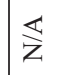 & 0 & $\overleftrightarrow{\mathrm{z}}$ & 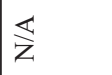 & 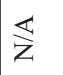 & $\vec{m}$ & \\
\hline 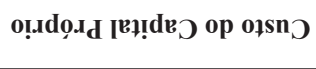 & $\infty$ & 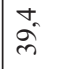 & - & ţ́ & $\begin{array}{l}\vec{t} \\
\text { s. }\end{array}$ & กิ & $\approx$ & $\hat{n}$ & $\because$ & $\stackrel{\Xi}{\rightarrow}$ & in & $\overleftrightarrow{\breve{z}}$ & 导 & \\
\hline вр!м! вр оңsnว & $=$ & $\hat{n}$ & $\vec{r}$ & 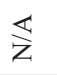 & $\begin{array}{l}0 \\
i n \\
i n\end{array}$ & $\vec{m}$ & $\stackrel{m}{ \pm}$ & $\begin{array}{l}\text { के } \\
\text { iे }\end{array}$ & $\stackrel{\Xi}{\sim}$ & के & $\begin{array}{l}0 \\
\ddot{2}\end{array}$ & 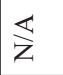 & $\ddot{2}$ & \\
\hline 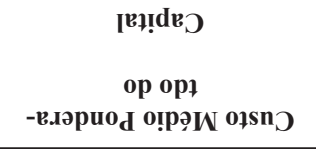 & in & $\stackrel{\sim}{\sim}$ & $\tilde{\infty}_{\infty}^{1}$ & $\tilde{n}^{1}$ & $\overrightarrow{\tilde{r}}$ & 6 & $\hat{8}_{0}^{\circ}$ & $\hat{n}$ & $\simeq$ & $\vec{\imath}$ & $\overrightarrow{i n}$ & $\overleftrightarrow{\text { z }}$ & $\approx$ & \\
\hline so.tpno & $\overleftrightarrow{\mathbb{z}}$ & $\overleftrightarrow{z}$ & $\overleftrightarrow{z}$ & $\stackrel{m}{r}$ & $\overleftrightarrow{z}$ & $\overleftrightarrow{\mathrm{z}}$ & v & 0 & 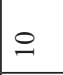 & 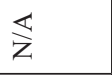 & $\overleftrightarrow{\mathrm{z}}$ & $\overleftrightarrow{z}$ & $\overleftrightarrow{z}$ & \\
\hline ș̣ణy səofdo & 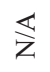 & $\overleftrightarrow{\mathrm{z}}$ & $\stackrel{\Xi}{=}$ & $\underset{\mathrm{Z}}{\overleftrightarrow{\mathrm{Z}}}$ & 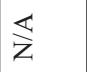 & 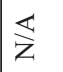 & 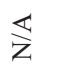 & 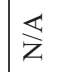 & $\overleftrightarrow{\text { Z }}$ & $\infty$ & $\frac{m}{6}$ & $\overleftrightarrow{\text { Z }}$ & $\bar{\sim}$ & \\
\hline 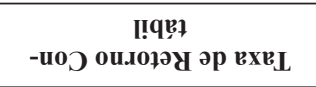 & $\stackrel{\sim}{i}$ & $\overleftrightarrow{\mathrm{z}}$ & $\hat{m}^{m}$ & $\begin{array}{l}\overrightarrow{\mathrm{d}} \\
\text { in }\end{array}$ & 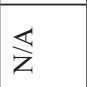 & $\hat{=}$ & N & $a$ & ป & $\overleftrightarrow{\mathrm{z}}$ & $\begin{array}{l}n \\
\infty \\
+\infty \\
+\end{array}$ & ले & $\ddot{\lambda}$ & \\
\hline УәвqКв & ి & $\hat{b}$ & $\stackrel{n}{+}$ & $\hat{\tilde{y}}$ & $\infty$ & $\hat{\delta}$ & 尺 & $\infty$ & ले & 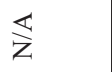 & $\Re$ & $\infty$ & $\ddot{\sim}$ & $\begin{array}{l}\tilde{N} \\
\text { d. }\end{array}$ \\
\hline әрер!!!qвұนәу әр әэ!рш! & $\overleftrightarrow{z}$ & $\overleftrightarrow{z}$ & भे & $\overleftrightarrow{\breve{z}}$ & 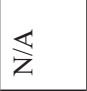 & $\begin{array}{l}0 \\
i\end{array}$ & $\overleftrightarrow{\zeta}$ & 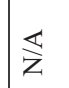 & 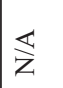 & 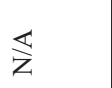 & $\begin{array}{l}\infty \\
\tilde{\gamma}\end{array}$ & $\begin{array}{l}\infty \\
+ \\
+\end{array}$ & $\underset{m}{\stackrel{n}{N}}$ & $\begin{array}{l}-\pi \\
\tilde{\sigma} \\
0 \\
0\end{array}$ \\
\hline 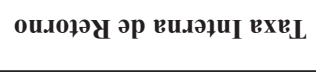 & $\stackrel{\infty}{+}$ & $\hat{n}$ & $\vec{a}$ & $\stackrel{+}{\sigma}$ & $\curvearrowleft$ & $\infty_{\infty}^{+}$ & $\pi$ & $\infty$ & $\stackrel{\infty}{\sim}$ & $\frac{\hat{\alpha}}{\infty}$ & $\overbrace{\infty}^{m}$ & $\hat{\tilde{v}}$ & $\approx$ & 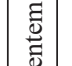 \\
\hline 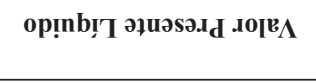 & $\stackrel{?}{+}$ & $\approx$ & ஃ & $=$ & 于 & 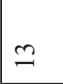 & $\infty$ & gे & in & J & $\infty$ & ते & $\stackrel{m}{\stackrel{m}{\sim}}$ & 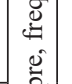 \\
\hline eșnbsəd & 光 & 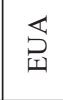 & 岕 & 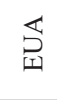 & 光 & 急 & 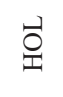 & 光 & 爱 & 㤂 & 콩롤 & $\frac{9}{4}$ & 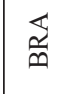 & $\begin{array}{l}\tilde{\Xi} \\
\mathscr{D} \\
\ddot{D} \\
\ddot{\Xi}\end{array}$ \\
\hline ONV & 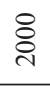 & $\overrightarrow{\mathrm{d}}$ & $\overrightarrow{\stackrel{े}{े}}$ & ڤి & ¿্ণ & ¿্ণ & & હे̊ & ठे & $\stackrel{\circ}{\stackrel{1}{\sim}}$ & $\stackrel{\circ}{\stackrel{\sim}{*}}$ & $\stackrel{\circ}{\stackrel{i}{\sim}}$ & $\stackrel{m}{\stackrel{n}{n}}$ & $\mid$ \\
\hline 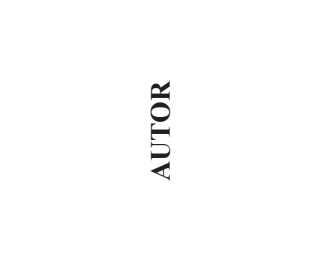 & 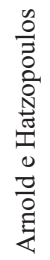 & 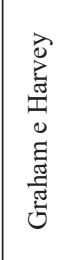 & 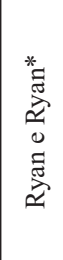 & $\frac{\ddot{0}}{\ddot{0}}$ & 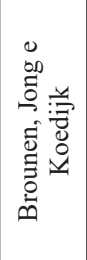 & 苞 & & 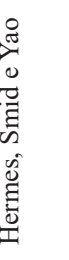 & 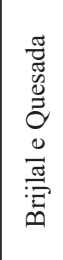 & 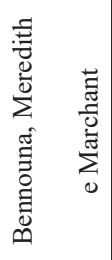 & 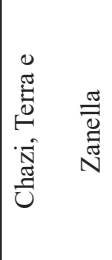 & 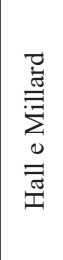 & 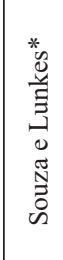 & 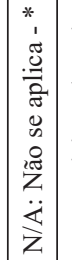 \\
\hline
\end{tabular}


Por fim, Sivabalan et al. (2009) aplicaram uma pesquisa sobre orçamento de capital em organizações de médio e grande porte da Austrália. Para eles os orçamentos organizacionais são de extrema importância paras as empresas, como para o planejamento, controle e avaliação das organizações, propondo uma perspectiva que justifique a sua utilização. Os autores concluíram que há uma desconexão entre a teoria e prática de orçamento organizacional.

A aplicação de técnicas tem sido estudadas em diversos outros países, como os de Arnold e Hatzopoulos (2000) no Reino Unido, Block (2003), Ryan e Ryan (2002) nos EUA, Brounen, Jong e Koedijk (2004) na Europa (Alemanha, França, Reino Unido e Holanda), Lazaridis (2004) no Chipre, Hermes, Smid e Yao (2007) na Holanda e China, Brijlal e Quesada (2009) na África, Bennouna, Meredith e Marchant (2010) no Canadá, Chazi, Terra e Zanella (2010) no Oriente Médio.

Estudos brasileiros são escassos, porém há 1 (um), que aplicou uma survey nos hotéis de Florianópolis, a fim de discutir a teoria e a prática utilizadas por eles para fazer seus orçamentos de capital, a survey dessa pesquisa foi estruturada com base nos autores Graham e Harvey (SOUZA; LUNKES, 2013).

\section{Procedimentos metodológicos}

O presente estudo baseia-se em uma pesquisa exploratória-descritiva baseada em métodos quantitativos, no qual foi aplicado uma Survey em escala Likert.

Levando em consideração essas questões, o trabalho foi elaborado através das seguintes etapas:

Pré-teste: o questionário foi submetido a uma criteriosa análise, que passou por um crivo de 4 (quatro) professores e pesquisadores da área de finanças ou áreas afins. Após essa análise, foram feitas as adequações sugeridas e o questionário passou por um pré-teste em 2 (duas) empresas, uma de pequeno porte e outra de médio para grande porte, a fim de garantir a validação do questionário e a correção de possíveis dificuldades de entendimento ou incongruências.

Coleta de dados: A coleta dos dados primários se deu por meio de aplicação de uma survey, tendo como instrumento um questionário composto por 17 constructos e 107 questões, dentre elas, 7 questões abertas com a opção "outras", 3 questões abertas e 2 questões de múltipla escolha. Destas 107 questões estão 81 em escala Likert distribuídas de "0 a 4" sendo o (0) pouco utilizado e o (4) muito utilizado. Junto ao questionário também foram colocadas questões para coletar informações dos respondentes, como o grau de educação do seu diretor financeiro, tempo de permanência no cargo e o porte da empresa, e algumas informações gerais para caracterizar a pesquisa. Este questionário foi elaborado através da modelagem proposta por Benetti (2005) e por Graham e Harvey (2001).

Amostra: A amostra foi composta por todas as empresas negociadas na B3, totalizando 523 empresas destas, 320 puderam ser contatadas e somente 55 responderam ao questionário, construindo uma amostra de $17,19 \%$ respondentes. 
Análise dos dados: A análise foi feita através do software SPSS ${ }^{\circledR}$, onde os dados obtidos através da aplicação dos questionários foram compilados e cruzados, com o intuito de obter estatísticas descritivas e resultados consistentes para o trabalho.

Devido à quantidade de respondentes, foi aplicada uma amostragem não probabilística intencional que, segundo Hair Jr. et al. (2005), envolve uma seleção de elementos da amostra para um fim específico, ou seja, os elementos da amostra de maneira que o pesquisador acredite que esses elementos representam a sua população alvo, porém não necessariamente esses elementos sejam representativos.

A partir de tais características, foram elaborados os seguintes constructos da survey:

a) Métodos de análise de investimentos: (i) Período Payback - PP; (ii)Valor Presente Líquido - VPL; (iii) Taxa Interna de Retorno - TIR; (iv) Índice de Rentabilidade - IR; e, (v) Opções Reais.

b) Técnica(s) utilizada(s) na definição da taxa de mínima de retorno aceitável para um investimento: (i) Custo médio ponderado do capital - WACC; (ii) Custo da dívida; (iii) Custo do capital próprio; (iv) Taxa aleatória; e, (v) Outra

c) Teorias sobre estrutura de capital.: (i) Trade-off; (ii) Pecking order;; (iii) Timing; (iv) Teoria da agência e governança corporativa; e, (v) Assimetria Informacional

d) Informações obtidas pelos sistemas de informações sobre avaliação de investimentos: (i) Fluxo de saídas projetadas; (ii) Fluxo de entradas projetadas; (iii) Custo do capital e taxa mínima de retorno; (iii) Expectativa de vida útil; e, (iv) Dados macroeconômicos

Quanto à aplicação do questionário, este foi submetido via e-mail, através do servidor de Formulários do Google, em âmbito nacional, no período de $1^{\circ}$ de março a 6 de maio do ano de 2016. Colaboraram com a pesquisa um total de 55 (cinquenta e cinco) empresas, dos mais variados portes e ramos. Vale lembrar que empresas do ramo financeiro foram excluídas da amostra. $\mathrm{O}$ tempo médio de resposta foi de aproximadamente 17 minutos. $\mathrm{O}$ número de respondentes foi de $17,19 \%$ do total da amostra, sendo que apenas 3 construtos não foram preenchidos por todos. Segundo Hair Jr. et al. (2005), a pesquisa só é considerada válida quando no mínimo se tem 5 (cinco) respondentes para cada variável da survey.

A análise e interpretação dos dados foi realizada por meio de aplicação de estatística descritiva e a análise fatorial. Antes de aplicação destas técnicas, os dados passaram por uma classificação, através da eliminação dos outliers e das questões que não contivessem pelo menos $90 \%$ de respostas válidas.

Segundo Hair Jr. et al. (2005) a análise fatorial é uma técnica estatística multivariada capaz de sintetizar as informações de um grande número de variáveis para um aglomerado bem menor de variáveis ou melhor, de fatores. A análise fatorial simplifica a compreensão dos dados, pois todas as variáveis são analisadas em conjunto, ou seja, não são separadas em dependentes ou independentes, sendo identificados certos padrões ou fatores subjacentes. Para Malhotra (2006), a análise fatorial é um procedimento destinado essencialmente para a redução e o resumo dos dados. 
Após a estimação dos componentes principais, foram aplicados os seguintes testes com o intuito de aumentar a robustez do modelo:

a) Teste de esfericidade de Bartlett (Teste $t$ ): este teste visa identificar se a matriz de correlações é estatisticamente igual a uma matriz identidade (Pestana \& Gageiro, 2003);

b) Rotação dos dados por meio do Método VARIMAX: com intuito de melhorar a interpretação dos dados por meio da estimação de uma nova matriz ortogonal;

c) Teste de Kaiser-Meyer-Olkin (KMO): visa, por meio da matriz de correlações inversa, verificar o ajustamento da análise fatorial aos dados (HAIR JR. et al., 2005).

d) Teste de Alpha de Crombach: verificar a consistência interna por meio da intercorrelação entre as variáveis.

e) Matriz anti-imagem: com o intuito de eliminar variáveis de baixa explicação. Malhotra (2006) afirma que, se alguma variável obtiver o valor da matriz inferior a 0,5, deve ser excluída. Hair Jr. et al. (2005) completa dizendo que, através dessa análise, a pesquisa terá maior confiabilidade.

\section{ANÁlise dos RESUltados}

Neste capítulo, são apresentadas as análises e testes aplicados aos dados primários coletados para a pesquisa em estudo, sendo dividido em 3 seções, são elas: (i) descrição das empresas; (ii) Caracterização da amostra; (iii) Análise Fatorial e Análise descritiva.

\subsection{Descrição das Empresas}

Nesta subseção, são apresentadas as estatísticas referentes à caracterização das empresas objeto do estudo. São observadas variáveis destinadas a conhecer melhor as empresas pesquisadas, bem como seu porte, seu faturamento, o grau de escolaridade de seu gestor, idade média de permanência no cargo dentre outros.

Inicialmente verifica-se que as empresas apresentam uma distribuição relativa entre os intervalos de obtenção de receitas anuais muito similares, sendo que $20,4 \%$ das empresas arrecadam menos que 70 milhões de receita anual; $14,8 \%$ arrecadam entre 71 e 300 milhões; 20,4\% arrecadam entre 301 milhões e 1,5 bilhão; 14,8\% arrecadam entre 1,6 e 3 bilhões; 13\%entre 4 e 15 bilhões e 16,7\% acima de 15 bilhões. Estas empresas pertencem aos mais diversos setores, porém com uma maior concentração nos setores de manufatura, mineração e construção.

Pelos dados identificou-se que um número expressivo de empresas não tem seus serviços regulados, dado que seus faturamentos anuais observados são relativamente altos. Outro ponto a se analisar é a política de pagamento de dividendos, provavelmente relacionada à informação anterior de que em torno de $41 \%$ das empresas são de capital fechado, não pagando dividendos.

Em relação a como a empresa vislumbra seu crescimento, foi observado que as empresas têm seu limite ou meta um tanto rígidos, somando 55,6\% da pesquisa, seguido de um limite ou meta rígidos, com o percentual de $29,6 \%$. Quanto às metas que a companhia declara como importantes para seu crescimento e desenvolvimento, as mais populares dentre 
os respondentes são a maximização dos lucros, correspondendo a aproximadamente $70 \%$ da pesquisa, vale lembrar que esta variável era de múltipla escolha, sendo assim cada respondente podia responder mais de uma opção. As outras duas mais votadas são a posição de mercado, com aproximadamente $58 \%$, e continuidade no mercado, correspondendo a $62 \%$. Já, com relação aos stakeholders prioritários para a empresa, segundo os respondentes, o mais importante é a administração, com $64,2 \%$, seguida de fornecedores de recursos financeiros e fornecedores de mercadorias/serviços, que se mantiveram bem próximos, com respectivamente $54,7 \%$ e $52,8 \%$ dos votos.

Os respondentes afirmam que seu quociente Preço/Lucro por Ação apurado nos últimos 3 anos é, em média, de $15,13 \%$, tendo como máxima $78 \%$ e mínima de $8 \%$. Já, em se tratando do quociente de dívidas de longo prazo em relação ao ativo total da empresa a máxima foi de $67 \%$ e a mínima de $12 \%$, com a média de $40,78 \%$, ou seja, em média os respondentes não estão se endividando muito a ponto de comprometer mais da metade de seu ativo total.

Quanto a classificação de risco de mercado, das 31 empresas respondentes, a maior parte está classificada com risco (BBB-) e (AA) com 6 respondentes em cada uma delas. Pode-se perceber que 14 empresas estão com classificação no grupo A e 17 estão com classificação no grupo B.

Por fim, em relação aos gestores das empresas é observado que quase $40 \%$ dos respondentes afirmam que mais de $20 \%$ das ações ordinárias da empresa são destinadas aos 3 principais executivos da companhia e que seu principal executivo tem, em sua maioria, entre 40 e 49 anos de idade, com títulos superiores a mestrado, ou seja, seus principais executivos são novos e buscam conhecimento contínuo. Também foi observado que 36,4\% destes executivos permanecerem no cargo principal por mais de 9 anos, e $41,8 \%$ ficam entre 4 e 9 anos no poder em mundo mercadológico bastante arriscado e com pouco espaço para o erro, a sua permanência no cargo tão longa, requer um grande desempenho na empresa.

\subsection{Análise fatorial e análise descritiva}

Como apontado nos procedimentos metodológicos, inicialmente foi aplicado o pré-teste da survey, no qual nesta etapa houve uma "limpeza" nas variáveis. Após a tabulação das respostas, os dados foram separados, deixando para esta primeira análise apenas os dados quantitativos, de resposta fechada e em escala Likert. Separadas essas variáveis, foram constituídos 10 (dez) constructos e 84 (oitenta e quatro) questões.

Estas questões foram submetidas à rotação Varimax e a anti-imagem, que por sua vez eliminaram 5 (cinco) questões, por não estarem no score mínimo aceitável. Sendo assim as questões que obtiveram sua comunalidade inferior a 0,5 , foram de fato descartadas das análises futuras. Foi eliminada uma variável dos constructos (2), (3) e (12), sendo que no constructo 8 (oito), duas variáveis foram eliminadas (8A e 8B). As variáveis excluídas da análise correspondem aproximadamente a $5,95 \%$ do total das questões fechadas e em escala likert abordadas nesta pesquisa, ou seja, um valor aceitável para prosseguir com este estudo. As demais variáveis encontram-se em equilíbrio, variando pouco quanto a sua comunalidade

Após "limpar" os dados da pesquisa, retirando as variáveis dadas como impuras, estimou-se a análise fatorial, para identificar as possíveis questões e dimensões e assim poder explicá-las. Nesta etapa também foram aplicados os testes KMO (Kaiser-Meyer-Olkin) 
e de esfericidade de Bartlett, a fim de verificar a adequação da amostra, e para indicar a confiabilidade dos dados, é aplicado o Alpha de Cronbach em cada constructo. Os Quadros de 2 a 11, exibem as 84 variáveis em seus respectivos constructos.

De acordo com Hair Jr. et al. (2005), os dados do teste de KMO devem ter um resultado superior a 0,800, assim como o teste de Esfericidade de Bartlett que deve obter o valor de significância inferior ap $<0,005$ e o Alpha de Cronbach que representa a confiabilidade das cargas fatoriais, deve apresentar um valor acima de 0,600.

Como se pode observar nas tabelas de 1 a 5 , apenas os constructos 11,12 e 5 passaram no teste de Kaiser-Meyer-Olkin (KMO) atingindo o valor mínimo exigido, já para o teste de esfericidade de Bartlett, todos os construtos demonstraram ter o valor de significância inferior a 0,05 , com sua maioria tendo seu valor de significância de Bartlett inferior a 0,001. Já para o teste de Alpha de Cronbach onde o valor necessita ser acima de 0,600, a grande maioria (exceto os constructos 3 e 16) foi significativa.

Adicionalmente, foi retratado individualmente cada construto e suas variáveis, salientando suas médias, medianas, modas, variâncias e desvios-padrão. Vale lembrar que nesta análise não constam mais as variáveis já eliminadas no $1^{\circ}$ processo, citado na seção anterior.

Como se pode ver na tabela 1 , são abordadas diretamente as técnicas de análise financeira por meio do construto ( 1 e 16), sendo que o primeiro trata da usualidade na aquisição de novos projetos e o segundo trata da aquisição de recursos financeiros, sendo que estes constructos estão divididos em escala likert variando de (0) sem uso à (4) uso muito frequente. Todos os pesquisados responderam o primeiro construto, já no construto 16 , apenas um não respondeu às questões, como se pode observar no item "número de respostas". A menor frequência encontrada foi na variável 1F, com média de 1,67 e mediana de 2, tendo como pouca usualidade a técnica de Payback (1F), ou seja, os respondentes usam pouco esta técnica. Por outro lado, os respondentes usam mais o Payback descontado (1G) com média 2,55 e mediana 3. Esta decisão é mais acertada, pois o segundo é mais confiável, já que considera o valor do dinheiro no tempo.

Já a máxima do constructo 1 com média de 2,87, foi para a variável Opções reais, com o uso mais frequente das empresas estudadas, também podemos observar que no item que avalia o grau de utilização da técnica de Valor Presente Líquido e Taxa Interna de Retorno, seus valores são expressivos de 2,73 e 2,65, respectivamente. Comparativamente aos resultados de Graham e Harvey (2001), os autores verificaram que a maioria dos entrevistados seleciona o valor presente líquido e a taxa interna de retorno como as técnicas de orçamento de capital mais utilizadas, no qual 74,9\% dos CFOs sempre ou quase sempre (respostas de 4 e 3 na escala likert) usam valor presente líquido (média de 3,08) e 75,7\% sempre ou quase sempre usam a taxa interna de retorno (média de 3,09). Nos resultados reportados a técnica de opções reais foi apenas a oitava técnica mais utilizada entre as 12 avaliadas por Graham e Harvey (2001). Outra diferença entre o resultado exposto no parágrafo anterior e o estudo de Graham e Harvey (2001) é que enquanto Payback é a técnica menos utilizada no Brasil, enquanto é a terceira mais utilizada nos EUA. 
Tabela 1 - Estatística descritiva dos construtos 1 e 16

\begin{tabular}{|c|c|c|c|c|c|c|c|c|c|c|c|}
\hline \multirow[b]{2}{*}{ Item } & \multirow[b]{2}{*}{ Descrição } & \multicolumn{6}{|c|}{ Estatística Descritiva } & \multicolumn{4}{|c|}{ Análise Fatorial } \\
\hline & & Resp. & Média & Med & Moda & Dp & Var & $\begin{array}{l}\text { Carga } \\
\text { Fat. }\end{array}$ & KMO & Bart. & Alpha \\
\hline $1 \mathrm{~A}$ & $\begin{array}{l}\text { Valor Presente Líqui- } \\
\text { do (VPL) }\end{array}$ & 55 & 2,73 & 3 & 3 & 0,781 & 0,609 & 0,901 & & & \\
\hline 1B & $\begin{array}{l}\text { Taxa Interna de Re- } \\
\text { torno (TIR) }\end{array}$ & 55 & 2,65 & 3 & 3 & 0,821 & 0,675 & 0,886 & & & \\
\hline $1 \mathrm{C}$ & $\begin{array}{l}\text { Taxa Mínima de } \\
\text { atratividade (taxa } \\
\text { mínima de retorno } \\
\text { para a aceitação de } \\
\text { um projeto) }\end{array}$ & 55 & 2,78 & 3 & 3 & 0,896 & 0,803 & 0,665 & & & \\
\hline $1 D$ & $\begin{array}{l}\text { Abordagem de Múlti- } \\
\text { plos de Lucros (p. ex. } \\
\text { Preço/Lucro, Preço/ } \\
\text { Valor Patrimonial) }\end{array}$ & 55 & 2,71 & 3 & 3 & 1,048 & 1,099 & 0,724 & & & \\
\hline $1 E$ & $\begin{array}{l}\text { Valor Presente Ajusta- } \\
\text { do (VPA) }\end{array}$ & 55 & 2,56 & 3 & 3 & 0,856 & 0,732 & 0,669 & & & \\
\hline $\mathbf{1 F}$ & $\begin{array}{l}\text { Período de Recu- } \\
\text { peração do Capital } \\
\text { ("PayBack") }\end{array}$ & 55 & 1,67 & 2 & 2 & 1,072 & 1,15 & 0,786 & & & \\
\hline $1 G$ & $\begin{array}{l}\text { Período de Recupera- } \\
\text { ção do Capital Des- } \\
\text { contado ("PayBack" } \\
\text { Descontado) }\end{array}$ & 55 & 2,55 & 3 & 2 & 1,23 & 1,512 & 0,937 & 0,696 & $0,000 *$ & 0,83 \\
\hline $1 \mathbf{H}$ & $\begin{array}{l}\text { Indice de } \\
\text { Lucratividade (Valor } \\
\text { Presente Relativo } \\
\text { ou Índice Benefício } \\
\text { Custo) }\end{array}$ & 55 & 2,64 & 3 & 3 & 0,62 & 0,384 & 0,529 & & & \\
\hline 1I & $\begin{array}{l}\text { Taxa de Retorno Con- } \\
\text { tábil (Taxa de Retorno } \\
\text { Contábil sobre os } \\
\text { Ativos, ROI) }\end{array}$ & 55 & 2,78 & 3 & 3 & 0,917 & 0,84 & 0,61 & & & \\
\hline $1 \mathrm{~J}$ & $\begin{array}{l}\text { Análise de Sensibili- } \\
\text { dade (por ex.: "Oti- } \\
\text { mista" vs, "Provável" } \\
\text { vs. "Pessimista") }\end{array}$ & 55 & 2,71 & 3 & 3 & 0,875 & 0,766 & 0,574 & & & \\
\hline $1 K$ & $\begin{array}{l}\text { Valor em Risco (VaR) } \\
\text { ou outra Análise de } \\
\text { Simulação }\end{array}$ & 55 & 2,64 & 3 & 3 & 0,95 & 0,902 & 0,763 & & & \\
\hline $1 \mathrm{~L}$ & $\begin{array}{l}\text { Nós incorporamos a } \\
\text { abordagem de "Op- } \\
\text { ções Reais" de um } \\
\text { projeto ao avaliá-lo }\end{array}$ & 55 & 2,87 & 3 & 3 & 1,019 & 1,039 & 0,627 & & & \\
\hline
\end{tabular}

16. Quando a empresa busca recursos financeiros para investimento, em que medida utiliza as seguintes fontes:

\begin{tabular}{|c|c|c|c|c|c|c|c|c|c|c|c|}
\hline \multirow[b]{2}{*}{ Item } & \multirow[b]{2}{*}{ Descrição } & \multicolumn{6}{|c|}{ Estatística Descritiva } & \multicolumn{4}{|c|}{ Análise Fatorial } \\
\hline & & Resp. & Média & Med. & Moda & DP & Var & $\begin{array}{c}\text { Carga } \\
\text { Fat. }\end{array}$ & KMO & Bart. & Alpha \\
\hline $16^{\mathrm{a}}$ & Capital Próprio & 54 & 2,81 & 3 & 2 & 0,953 & 0,908 & 0,772 & \multirow{3}{*}{0,627} & \multirow{3}{*}{$0,000^{*}$} & \multirow{3}{*}{$-1,04^{* *}$} \\
\hline $16 B$ & Capital de Terceiros & 54 & 3,06 & 3 & 3 & 0,92 & 0,846 & 0,512 & & & \\
\hline $16 \mathrm{C}$ & Emissão de ações & 54 & 1,81 & 2 & 0 & 1,506 & 2,267 & 0,685 & & & \\
\hline
\end{tabular}

Fonte: Elaborado pelos autores. 
Para o constructo 16 onde os respondentes identificaram se eles utilizam mais capital próprio, capital de terceiros ou emissão de ações quando precisam captar recursos financeiros, neste caso, as empresas preferem utilizar capital de terceiros, com média de 3,06 e mediana de 3, seguida de capital próprio, com média de 2,81 e mediana de 3 e, como último recurso, optam por emissão de ações, com média de 1,81 e mediana de 2, confirmando que a lógica do trade-off se sobrepõe a da pecking-order, em compasso com o estudo de Fama and French (2002) e contrariando os estudos de Myers (1984) e Myers e Majluf (1984).

Na tabela 2, são apresentadas a média, mediana, moda, variância e desvio-padrão dos constructos (2) e (3) que avaliam o custo do capital.

Tabela 2 - Estatística descritiva dos construtos 2 e 3

\begin{tabular}{c} 
2. Quão frequentemente sua empresa utilizaria os seguintes custos de capital ao avaliar um projeto novo em um mercado interna- \\
cional? (taxa de desconto, WACC). Para avaliar esse projeto nós utilizaríamos... \\
\hline \multirow{2}{*}{ Item }
\end{tabular}

3. Sua empresa estima o custo de capital próprio?

\begin{tabular}{|c|c|c|c|c|c|c|c|c|c|c|c|}
\hline \multirow[b]{2}{*}{ Item } & \multirow[b]{2}{*}{ Descrição } & \multicolumn{6}{|c|}{ Estatística Descritiva } & \multicolumn{4}{|c|}{ Análise Fatorial } \\
\hline & & Resp. & Média & Med. & Moda & DP & Var & $\begin{array}{l}\text { Carga } \\
\text { Fat. }\end{array}$ & KMO & Bart. & Alpha \\
\hline $3 \mathrm{~A}$ & $\begin{array}{l}\text { Com a média histórica dos retornos } \\
\text { das ações }\end{array}$ & 29 & 2,83 & 3 & 3 & 0,928 & 0,862 & 0,75 & \multirow{5}{*}{0,586} & \multirow{5}{*}{0,043} & \multirow{5}{*}{$0,578^{*}$} \\
\hline $3 \mathrm{~B}$ & $\begin{array}{l}\text { Usando o "Capital Asset Pricing } \\
\text { Model" (CAPM, abordagem do } \\
\text { "beta", modelo de } 1 \text { fator) }\end{array}$ & 30 & 2,83 & 3 & 3 & 0,699 & 0,489 & 0,68 & & & \\
\hline $3 \mathrm{C}$ & $\begin{array}{l}\text { Usando o CAPM, mas incluindo } \\
\text { alguns "fatores de risco" adicionais }\end{array}$ & 30 & 3 & 3 & 3 & 0,743 & 0,552 & 0,721 & & & \\
\hline 3D & \begin{tabular}{|l|} 
Aquele que nossos investidores \\
nos dizem que requerem
\end{tabular} & 30 & 3,27 & 4 & 4 & 1,081 & 1,168 & 0,517 & & & \\
\hline $3 \mathrm{~F}$ & $\begin{array}{l}\text { Retroagindo do modelo de dividen- } \\
\text { dos e/ou lucros descontados, por } \\
\text { ex.: Preço = Dividendos/(Custo de } \\
\text { Capital - Taxa de Crescimento) }\end{array}$ & 30 & 2,57 & 3 & 3 & 0,935 & 0,875 & 0,609 & & & \\
\hline
\end{tabular}

Fonte: Elaborado pelos autores

Os constructos (2) e (3) também são em escala Likert que variam de (0) pouco frequente a (4) muito frequente. No constructo (2) a média tem seu menor índice em 2,59 e o maior em 2,91, ou seja, não variou muito suas respostas, seus respondentes usam frequen- 
temente todas as técnicas para custo de capital para avaliar um projeto novo. A técnica mais utilizada (média de 2,91) para avaliar um novo projeto é o custo de capital para toda a empresa evidenciando um resultado similar ao Graham e Harvey (2001) no qual evidenciaram que 58,8\% dos entrevistados sempre ou quase sempre usam a taxa de desconto para toda a empresa, mesmo que o projeto hipotético provavelmente tivesse risco diferente.

Já para o constructo (3) onde o respondente avalia o custo de capital próprio, houve um aumento na frequência de uso das técnicas listadas, tendo a menor média em 2,57 e sua maior média em 3,27, que nesse caso evidenciou que a empresa estima o capital próprio baseada na tomada de decisão superior, e/ou grupo de acionistas majoritários ou diretores financeiros.

O constructo 4, apresentado na Tabela 3, não está em escala Likert e sim em fatores de uso, sendo (1) Custo de Capital; (2) Fluxo de Caixa; (3) uso de ambos e (4) uso de nenhum deles.

Tabela 3 - Estatística descritiva do constructo 4

\begin{tabular}{|c|c|c|c|c|c|c|c|c|c|c|c|}
\hline \multicolumn{12}{|c|}{ 4. Quando avaliando um projeto, você ajusta a taxa de desconto ou os fluxos de caixa para os seguintes fatores de risco? } \\
\hline \multirow{2}{*}{ Item } & \multirow{2}{*}{ Descrição } & \multicolumn{6}{|c|}{ Estatística Descritiva } & \multicolumn{4}{|c|}{ Análise Fatorial } \\
\hline & & Resp. & Média & Med & Moda & Dp & Var & Carga Fat. & KMO & Bart. & Alpha \\
\hline $4 \mathrm{~A}$ & $\begin{array}{l}\text { Risco de inflação inespe- } \\
\text { rada }\end{array}$ & 55 & 2,56 & 3 & 3 & 0,688 & 0,473 & 0,695 & \multirow{11}{*}{0,591} & \multirow{10}{*}{$0,000 *$} & \multirow{10}{*}{0,759} \\
\hline 4B & $\begin{array}{l}\text { Risco de taxa de juros } \\
\text { (mudança no nível geral } \\
\text { das taxas de juros) }\end{array}$ & 54 & 2,5 & 3 & 3 & 0,746 & 0,557 & 0,876 & & & \\
\hline $4 \mathrm{C}$ & $\begin{array}{l}\text { Risco da estrutura a termo } \\
\text { (mudança nas taxas de } \\
\text { juros de longo prazo vs. } \\
\text { curto prazo) }\end{array}$ & 55 & 2,53 & 3 & 3 & 0,858 & 0,735 & 0,837 & & & \\
\hline 4D & $\begin{array}{l}\text { Risco do PIB ou risco do } \\
\text { ciclo econômico }\end{array}$ & 55 & 2,49 & 3 & 3 & 0,836 & 0,699 & 0,555 & & & \\
\hline $4 E$ & $\begin{array}{l}\text { Risco do preço de "com- } \\
\text { modities" }\end{array}$ & 55 & 2,93 & 3 & 3 & 0,79 & 0,624 & 0,742 & & & \\
\hline $4 F$ & Risco da taxa de câmbio & 55 & 2,64 & 3 & 3 & 0,62 & 0,384 & 0,588 & & & \\
\hline $4 \mathrm{G}$ & $\begin{array}{l}\text { Risco de insolvência (pro- } \\
\text { babilidade de falência) }\end{array}$ & 55 & 2,51 & 3 & 3 & 1,016 & 1,032 & 0,755 & & & \\
\hline $4 \mathbf{H}$ & $\begin{array}{l}\text { Porte (empresas pequenas } \\
\text { sendo mais arriscadas) }\end{array}$ & 54 & 2,35 & 3 & 3 & 1,119 & 1,251 & 0,737 & & & \\
\hline $4 I$ & $\begin{array}{l}\text { Índice Valor de Mercado/ } \\
\text { Valor Patrimonial } \\
\text { (quociente do valor de } \\
\text { mercado da empresa para o } \\
\text { valore contábil dos ativos) }\end{array}$ & 55 & 2,89 & 3 & 3 & 0,685 & 0,469 & 0,627 & & & \\
\hline $4 \mathrm{~J}$ & $\begin{array}{l}\text { "Momentum" (desempe- } \\
\text { nho recente do preço das } \\
\text { ações) }\end{array}$ & 55 & 3,38 & 3 & 3 & 0,652 & 0,426 & 0,625 & & & \\
\hline s. & to de Capita & & & & & & & & & & \\
\hline
\end{tabular}

Fonte: Elaborado pelos autores.

Como se pode avaliar, esse construto trata da melhor forma para avaliação de projetos. Em todas as análises as empresas utilizam tanto o custo de capital quanto o fluxo de caixa para a avaliação de um projeto. De maneira geral, o risco de taxa de juros, o risco de estrutura a termo, o risco do PIB e o risco de insolvência apresentaram uma importância média 
muito próximo quando projetos são avaliados, ajustando a taxa de desconto ou os fluxos de caixa para os fatores referidos. Cabe destacar a média mínima para o item "porte" e a média máxima para o fator "momentum". Este último se revelou como o principal fator que os respondentes consideram para ajustar a taxa de desconto ou os fluxos de caixa para o cenário brasileiro. Graham e Harvey (2001) reportam que apenas 11,1\% dos respondentes consideram importante o fator momentum, diferindo significativamente dos resultados para o cenário brasileiro, indicando haver uma preocupação e um impacto maior no curto prazo.

Já para os constructos 5, 11 e 12, apresentados na tabela 4, versam a respeito de endividamento. Para o 5, como se comportam com dívidas de curto e longo prazo, no 11, que fatores afetam a escolha do montante apropriado de endividamento e para o constructo 12 , que fatores afetam a política de endividamento da empresa.

Tabela 4 - Estatística descritiva dos construtos 5, 11 e 12

\begin{tabular}{|c|c|c|c|c|c|c|c|c|c|c|c|}
\hline \multicolumn{12}{|c|}{ 5. Que fatores afetam a escolha da sua empresa entre dívida de curto e longo prazos? } \\
\hline \multirow{2}{*}{ Item } & \multirow{2}{*}{ Descrição } & \multicolumn{6}{|c|}{ Estatística Descritiva } & \multicolumn{4}{|c|}{ Análise Fatorial } \\
\hline & & Resp. & Média & Med & Moda & Dp & Var & Carga Fat. & KMO & Bart. & Alpha \\
\hline $5 \mathbf{A}$ & $\begin{array}{l}\text { Nós tomamos dívida de curto } \\
\text { prazo quando as taxas de juros } \\
\text { de curto prazo estão baixas com- } \\
\text { paradas às taxas de longo prazo }\end{array}$ & 54 & 2,48 & 3 & 3 & 0,771 & 0,594 & 0,59 & & & \\
\hline 5B & $\begin{array}{l}\text { Casando o prazo da nossa dívida } \\
\text { com a vida dos nossos ativos }\end{array}$ & 55 & 2,76 & 3 & 3 & 0,902 & 0,813 & 0,552 & & & \\
\hline $5 \mathrm{C}$ & $\begin{array}{l}\text { Nós tomamos dívida de curto } \\
\text { prazo enquanto esperamos as } \\
\text { taxas de mercado de longo prazo } \\
\text { declinarem }\end{array}$ & 53 & 2,55 & 3 & 3 & 0,822 & 0,676 & 0,774 & & & \\
\hline 5D & $\begin{array}{l}\text { Nós tomamos dívida de curto } \\
\text { prazo para que os retornos dos } \\
\text { novos projetos possam ser cap- } \\
\text { turados mais integralmente pelos } \\
\text { acionistas, ao invés de nos com- } \\
\text { prometermos com o pagamento } \\
\text { de lucros de longo prazo sob a } \\
\text { forma de juros para os credores }\end{array}$ & 55 & 2,67 & 3 & 3 & 0,862 & 0,743 & 0,712 & 0,809 & $0,000 *$ & 0,758 \\
\hline $5 E$ & $\begin{array}{l}\text { Nós esperamos que a nossa clas- } \\
\text { sificação de crédito ("rating") irá } \\
\text { melhorar, assim nós tomamos } \\
\text { dívida de curto prazo até que } \\
\text { isso aconteça }\end{array}$ & 55 & 2 & 2 & 2 & 1,374 & 1,889 & 0,747 & & & \\
\hline $5 \mathrm{~F}$ & $\begin{array}{l}\text { Tomar dívida de curto prazo } \\
\text { reduz a chance de que nossa } \\
\text { empresa deseje implementar } \\
\text { projetos arriscados }\end{array}$ & 54 & 2,5 & 3 & 3 & 0,72 & 0,519 & 0,567 & & & \\
\hline $5 G$ & $\begin{array}{l}\text { Nós tomamos dívida de longo } \\
\text { prazo pra minimizar o risco de } \\
\text { ter que refinanciar em "perío- } \\
\text { dos ruins" }\end{array}$ & 54 & 3,02 & 3 & 3 & $\mathbf{0 , 8 3 5}$ & 0,698 & 0,663 & & & \\
\hline
\end{tabular}


11. Que fatores afetam como você escolhe o montante apropriado de endividamento para sua empresa?

\begin{tabular}{|c|c|c|c|c|c|c|c|c|c|c|c|}
\hline \multirow{2}{*}{ Item } & \multirow{2}{*}{ Descrição } & \multicolumn{6}{|c|}{ Estatística Descritiva } & \multicolumn{4}{|c|}{ Análise Fatorial } \\
\hline & & Resp. & Média & Med. & Moda & DP & Var & Carga Fat. & KMO & Bart. & Alpha \\
\hline $11 \mathrm{~A}$ & $\begin{array}{l}\text { A vantagem tributária da deduti- } \\
\text { bilidade dos juros }\end{array}$ & 54 & 2,5 & 3 & 3 & 0,771 & 0,594 & 0,624 & \multirow{13}{*}{0,845} & \multirow{13}{*}{$0,000 *$} & \multirow{13}{*}{0,866} \\
\hline 11B & $\begin{array}{l}\text { Os custos potencias de falência, } \\
\text { concordata ou dificuldades finan- } \\
\text { ceiras }\end{array}$ & 55 & 2,47 & 2 & 2 & 0,836 & 0,698 & 0,766 & & & \\
\hline $11 \mathrm{C}$ & $\begin{array}{l}\text { Os níveis de endividamento de } \\
\text { outras empresas em nosso setor }\end{array}$ & 55 & 2,42 & 3 & 3 & 0,994 & 0,989 & 0,889 & & & \\
\hline 11D & $\begin{array}{l}\text { Nossa classificação de crédito } \\
\text { ("rating", conforme atribuído } \\
\text { pelas agências de classificação } \\
\text { de risco) }\end{array}$ & 54 & 1,93 & 2 & 0 & 1,588 & 2,523 & 0,812 & & & \\
\hline $11 E$ & $\begin{array}{l}\text { Os custos de transação e as co- } \\
\text { missões de colocação da dívida }\end{array}$ & 52 & 2,54 & 3 & 3 & 0,779 & 0,606 & 0,734 & & & \\
\hline $11 G$ & $\begin{array}{l}\text { Flexibilidade financeira (nós } \\
\text { restringimos o endividamento; } \\
\text { assim nós temos fundos internos } \\
\text { disponíveis para implementar } \\
\text { novos projetos quando eles sur- } \\
\text { gem) }\end{array}$ & 54 & 2,77 & 3 & 3 & 0,703 & 0,495 & 0,709 & & & \\
\hline $11 \mathrm{H}$ & $\begin{array}{l}\text { A volatilidade dos nossos lucros } \\
\text { e fluxos de caixa }\end{array}$ & 52 & 2,78 & 3 & 3 & 0,793 & 0,629 & 0,618 & & & \\
\hline $11 \mathrm{I}$ & $\begin{array}{l}\text { Nós limitamos o endividamento; } \\
\text { assim nossos clientes/fornecedo- } \\
\text { res não se preocupam com a pos- } \\
\text { sibilidade da nossa empresa falir }\end{array}$ & 53 & 2,71 & 3 & 3 & 0,75 & 0,562 & 0,649 & & & \\
\hline $11 \mathrm{~J}$ & $\begin{array}{l}\text { Nós tentamos ter um endivida- } \\
\text { mento suficiente para que não se- } \\
\text { jamos um alvo atraente para uma } \\
\text { aquisição ("takeover") }\end{array}$ & 53 & 2,6 & 3 & 2 & 0,84 & 0,705 & 0,654 & & & \\
\hline $11 K$ & $\begin{array}{l}\text { Se nós nos endividarmos, nossos } \\
\text { competidores saberão que será } \\
\text { muito improvável que iremos } \\
\text { reduzir nossa produção e/ou ven- } \\
\text { das }\end{array}$ & 54 & 2,62 & 3 & 3 & 0,765 & 0,586 & 0,769 & & & \\
\hline $11 \mathrm{~L}$ & $\begin{array}{l}\text { Um índice de endividamento alto } \\
\text { nos ajuda a barganhar concessões } \\
\text { de nossos empregados }\end{array}$ & 54 & 2,48 & 3 & 3 & 0,906 & 0,82 & 0,614 & & & \\
\hline $11 M$ & $\begin{array}{l}\text { Para assegurar que a administra- } \\
\text { ção superior trabalhe durante e } \\
\text { eficientemente, nós nos endivi- } \\
\text { damos o suficiente para garantir } \\
\text { que uma grande porção do nosso } \\
\text { fluxo de caixa seja comprometida } \\
\text { com o pagamento de juros. }\end{array}$ & 54 & 2,69 & 3 & 3 & 0,948 & 0,899 & 0,628 & & & \\
\hline $11 N$ & $\begin{array}{l}\text { Nós restringimos nosso endivi- } \\
\text { damento de forma que os lucros } \\
\text { de novos/futuros projetos sejam, } \\
\text { completamente, capturados pelos } \\
\text { acionistas e não tenham que ser } \\
\text { pagos sob a forma de juros para } \\
\text { os credores }\end{array}$ & 54 & 2,85 & 3 & 3 & 0,763 & 0,581 & 0,751 & & & \\
\hline
\end{tabular}


12. Que outros fatores afetam a política de endividamento da sua empresa?

\begin{tabular}{|c|c|c|c|c|c|c|c|c|c|c|c|}
\hline \multirow{2}{*}{ Item } & \multirow{2}{*}{ Descrição } & \multicolumn{6}{|c|}{ Estatística Descritiva } & \multicolumn{4}{|c|}{ Análise Fatorial } \\
\hline & & Resp. & Média & Med. & Moda & DP & Var & Carga Fat. & KMO & Bart. & Alpha \\
\hline $12 \mathrm{~A}$ & $\begin{array}{l}\text { Nós nos endividamos quando } \\
\text { nossos lucros recentes (fundos } \\
\text { internos) não são suficientes para } \\
\text { financiar nossas atividades } \\
\end{array}$ & 54 & 2,61 & 3 & 3 & 0,811 & 0,657 & 0,62 & & & \\
\hline 12B & $\begin{array}{l}\text { Utilizar endividamento dá aos } \\
\text { investidores uma impressão me- } \\
\text { lhor das perspectivas da nossa } \\
\text { empresa do que emitir ações }\end{array}$ & 54 & 2,15 & 2 & 3 & 1,106 & 1,223 & 0,579 & & & \\
\hline 12D & $\begin{array}{l}\text { Nós utilizamos endividamento } \\
\text { quando nossas ações estão suba- } \\
\text { valiadas pelo mercado }\end{array}$ & 54 & 2,19 & 2,5 & 3 & 1,047 & 1,097 & 0,672 & & & \\
\hline $12 E$ & $\begin{array}{l}\text { Nós adiamos o uso de endivida- } \\
\text { mento devido aos custos de tran- } \\
\text { sação e comissão de colocação } \\
\text { da dívida }\end{array}$ & 54 & 2,59 & 3 & 3 & 0,88 & 0,774 & 0,607 & 0,809 & $0,000^{*}$ & 0,812 \\
\hline $12 F$ & $\begin{array}{l}\text { Nós adiamos o resgate da dívida } \\
\text { devido aos custos e comissões } \\
\text { para recapitalização }\end{array}$ & 54 & 2,61 & 3 & 3 & 0,787 & 0,619 & 0,712 & & & \\
\hline $12 G$ & $\begin{array}{l}\text { Mudanças no preço de nossas } \\
\text { ações }\end{array}$ & 53 & 1,75 & 2 & 2 & 1,27 & 1,612 & 0,807 & & & \\
\hline $12 \mathrm{H}$ & $\begin{array}{l}\text { Nós não nos endividamos } \\
\text { quando temos lucros acumula- } \\
\text { dos substanciais }\end{array}$ & 54 & 2,63 & 3 & 3 & 0,734 & $\mathbf{0 , 5 3 9}$ & 0,6 & & & \\
\hline
\end{tabular}

No constructo 5, que aborda os fatores que afetam a escolha de dívidas de curto e longo prazos, a variável que apresentou maior média foi a $5 \mathrm{G}(3,02$, sendo a mediana 3$)$, ou seja, as empresas escolhem tomar dívidas de longo prazo para evitar refinanciamento da dívida em períodos difíceis. Para o construto 11 o fator mais importante que afeta como as firmas escolhem o montante apropriado de endividamento é a volatilidade do fluxo de caixa com uma média de 2,78. Comparativamente ao estudo de Graham e Harvey (2001) a volatilidade dos fluxos de caixa é o terceiro fator mais preponderante a afetar o endividamento, ficando atrás apenas de flexibilidade financeira e rating de crédito. Este último revela uma diferença para o cenário brasileiro, no qual o rating de crédito é o fator que obteve média baixa de 1,93. Já as demais variáveis deste construto obtiveram concordância geral, com suas médias variando bem pouco, ficando entre 2,42 e 2,85.

Por fim, no constructo 12 , que abordou outras políticas de endividamento tomadas pelas empresas, os respondentes parecem não se importar muito com a mudança no preço de suas ações, tendo essa variável a menor média deste constructo, com apenas 1,75, por outro lado, as empresas preferem não se endividar quando os lucros acumulados são substanciais, apresentando média de 2,63 e mediana de 3. Este resultado vai ao encontro dos resultados evidenciados por Graham e Harvey (2001).

Por fim, tem-se os constructos 8 e 9, que abordam emissão de dívida conversível e emissão de ações. A tabela 5 evidencia que o objetivo principal das empresas quando emitem dívida conversível ou ações, é gerar recursos financeiros. 
Tabela 5 - Estatística descritiva dos construtos 8 e 9

8. Sua empresa considerou seriamente emitir dívida conversível?

\begin{tabular}{|c|c|c|c|c|c|c|c|c|c|c|c|}
\hline \multirow[b]{2}{*}{ Item } & \multirow[b]{2}{*}{ Descrição } & \multicolumn{6}{|c|}{ Estatística Descritiva } & \multicolumn{4}{|c|}{ Análise Fatorial } \\
\hline & & Resp. & Média & Med & Moda & Dp & Var & $\begin{array}{l}\text { Carga } \\
\text { Fat. }\end{array}$ & KMO & Bart. & Alpha \\
\hline $8 C$ & $\begin{array}{l}\text { Títulos de dívida conversível são } \\
\text { menos onerosos do que dívidas } \\
\text { comuns. }\end{array}$ & 28 & 27 & 2,89 & 3 & 3 & 0,497 & 0,751 & & & \\
\hline 8D & $\begin{array}{l}\text { Outras empresas em nosso setor } \\
\text { utilizam títulos de dívida conversí- } \\
\text { veis com sucesso }\end{array}$ & 28 & 27 & 2,46 & 2,5 & $2^{\mathrm{a}}$ & 0,838 & 0,797 & & & \\
\hline $8 \mathrm{E}$ & $\begin{array}{l}\text { Evitar diluição patrimonial no cur- } \\
\text { to prazo }\end{array}$ & 28 & 27 & 2,79 & 3 & 3 & 0,738 & 0,662 & 0,680 & 0,004 & 0,691 \\
\hline $8 F$ & $\begin{array}{l}\text { Nossas ações estão atualmente su- } \\
\text { bavaliadas }\end{array}$ & 28 & 27 & 2,39 & 2 & 2 & 0,685 & 0,595 & & & \\
\hline $8 G$ & $\begin{array}{l}\text { Capacidade para resgatar ou forçar } \\
\text { a conversão de títulos de dívida } \\
\text { conversíveis se/quando nós preci- } \\
\text { sarmos }\end{array}$ & 28 & 27 & 2,79 & 3 & 3 & 0,787 & 0,645 & & & \\
\hline
\end{tabular}

\section{Sua empresa considerou emitir ações?}

Estatística Descritiva

Descrição

\begin{tabular}{|c|c|c|c|c|c|c|c|c|c|c|c|}
\hline \multirow[b]{2}{*}{ Item } & \multirow[b]{2}{*}{ Descrição } & & & & & & & & & & \\
\hline & & Resp. & Média & Med. & Moda & DP & Var & $\begin{array}{l}\text { Carga } \\
\text { Fat. }\end{array}$ & KMO & Bart. & Alph: \\
\hline 9A & $\begin{array}{l}\text { Se o preço de nossas ações aumen- } \\
\text { tou recentemente, o preço no qual } \\
\text { podemos emiti-las é "alto" }\end{array}$ & 32 & 23 & 2,56 & 3 & 3 & 0,948 & 0,719 & \multirow{13}{*}{0,705} & \multirow{13}{*}{$0,000 *$} & \multirow{13}{*}{0,864} \\
\hline 9B & $\begin{array}{l}\text { Ações são a nossa fonte de fundos } \\
\text { "menos arriscada" }\end{array}$ & 32 & 23 & 3,09 & 3 & 3 & 0,641 & 0,737 & & & \\
\hline $9 \mathrm{C}$ & $\begin{array}{l}\text { Prover ações para bônus/planos de } \\
\text { opções de ações ("Stock Options") } \\
\text { para empregados }\end{array}$ & 32 & 23 & 2,59 & 3 & 3 & 0,798 & 0,754 & & & \\
\hline 9D & $\begin{array}{l}\text { Ações são nossa fonte de fundo } \\
\text { mais barata }\end{array}$ & 31 & 24 & 2,77 & 3 & 3 & 0,805 & 0,847 & & & \\
\hline $9 E$ & $\begin{array}{l}\text { Manter um índice-alvo Exigível/Pa- } \\
\text { trimônio Líquido }\end{array}$ & 32 & 23 & 2,66 & 3 & 3 & 0,787 & 0,522 & & & \\
\hline $9 F$ & $\begin{array}{l}\text { Utilizar um montante de capital } \\
\text { próprio similar a outras empresas } \\
\text { do nosso setor }\end{array}$ & 32 & 23 & 2,56 & 3 & 3 & 0,801 & 0,636 & & & \\
\hline $9 G$ & $\begin{array}{l}\text { Nossos Lucros recentes não foram } \\
\text { suficientes para financiar nossas } \\
\text { atividades }\end{array}$ & 32 & 23 & 2,5 & 3 & 3 & 1,078 & 0,743 & & & \\
\hline $9 H$ & $\begin{array}{l}\text { Emitir ações dá aos investidores } \\
\text { uma impressão melhor das perspec- } \\
\text { tivas da nossa empresa do que tomar } \\
\text { dívida }\end{array}$ & 32 & 23 & 2,53 & 3 & 3 & 0,718 & 0,822 & & & \\
\hline 9I & $\begin{array}{l}\text { As alíquotas de imposto sobre gan- } \\
\text { hos de capital dos investidores (em } \\
\text { relação às alíquotas de imposto so- } \\
\text { bre dividendos e/ou juros sobre ca- } \\
\text { pital próprio) }\end{array}$ & 31 & 24 & 2,58 & 3 & 2 & 0,848 & 0,643 & & & \\
\hline 9J & $\begin{array}{l}\text { Diluir a participação acionária de } \\
\text { certos acionistas }\end{array}$ & 32 & 23 & 3,25 & 4 & 4 & 1,136 & 0,786 & & & \\
\hline $9 K$ & $\begin{array}{l}\text { O montante pelo qual as nossas } \\
\text { ações estão subavaliadas ou supera- } \\
\text { valiadas pelo mercado }\end{array}$ & 32 & 23 & 2,44 & 3 & 3 & 0,914 & 0,757 & & & \\
\hline 9L & $\begin{array}{l}\text { Incapacidade de se obter fundos } \\
\text { utilizando dívida, títulos de dívida } \\
\text { conversíveis ou outras fontes }\end{array}$ & 32 & 23 & 2,34 & 2,5 & 3 & 1,004 & 0,772 & & & \\
\hline $9 M$ & $\begin{array}{l}\text { Fonte: Elabo } \\
\text { Diluição dos Lucros por Ação }\end{array}$ & rado p & lo a 24 tor & 2,74 & dos d & $\mathrm{S}_{3} \mathrm{C}$ & $\begin{array}{l}\text { etados } \\
1,154 \\
\end{array}$ & $(2016)$ & & & \\
\hline
\end{tabular}

Análise Fatorial 
Esses dois construtos tiveram a menor taxa de respondentes, por esse motivo, foi adicionada uma coluna com o número de questionários que não responderam à pesquisa. No constructo 8 , as variáveis que apresentaram maior média foram as que recorrem a dívidas conversíveis por serem menos onerosas (2,89 e mediana de 3), para evitar a diluição do patrimônio em curto prazo (2,79 e mediana de 3 ) e maior facilidade para resgate (2,79 e mediana de 3$)$. Já para o constructo 9 , que fala sobre emitir ações, os respondentes demonstraram que a melhor opção para emitir ações seria para diluir o poder acionário de determinados acionistas (média de 3,09 e mediana de 3), e bem pouco por incapacidade de conseguir recursos de outras fontes (média de 2,34 e mediana de 2,5), ou seja, não usam o fato de emitir ações como recurso para obter fundos, as demais variáveis obtiveram média próxima a 3 (uso frequente).

\section{Considerações finais}

O presente estudo buscou identificar quais as técnicas de análise financeiras são mais usuais nas empresas de capital aberto brasileiras. Para isso foi elaborado um questionário, com perguntas abertas e fechadas, que foi aplicado a diretores financeiros das empresas listadas na B3.

Em se tratando das técnicas de análise financeira, desde as mais comuns e de fácil aplicação, que não levam em consideração o valor do dinheiro no tempo, até as que têm certo grau de complexidade e que consideram o valor do dinheiro no tempo, é observado que "Opções reais" é a técnica mais utilizada pelos respondentes, sendo que o PayBack foi o que obteve a menor média. Este resultado demonstra que as empresas estão cada vez mais especializadas, deixando de usar técnicas simples e sem considerar o valor do dinheiro no tempo e começando a utilizar técnicas mais complexas. O VPL, a TIR e o PayBack Descontado, também tiveram uma representatividade considerável nas respostas.

O VPL (Valor Presente Líquido) no trabalho de Souza e Lunkes (2013), é apontado como a técnica mais utilizada nas empresas brasileiras. No presente estudo, essa técnica ficou em terceiro lugar, atrás da TIR (Taxa Interna de Retorno) e do ROI (Retorno Sobre o Investimento), que ficaram empatadas em segundo lugar, e atrás das Opções Reais, que obteve primeiro lugar.

Em se tratando de custo de capital, analisado através do custo médio ponderado ou das taxas de desconto, as empresas respondentes tiveram uma leve tendência a responder que preferem optar por aquilo que seus investidores decidirem, fazendo o uso do custo médio ponderado em boa parte da empresa. Nas pesquisas anteriores, essas duas técnicas possuíam o mesmo grau de usualidade, ou seja, eram usadas concomitantemente.

Outra questão importante a ser relatada, diz respeito à escala de prioridades quando as empresas precisam obter recursos, É percebido que quando há flutuações constantes de crédito, crises econômicas, necessidade de expansão da planta produtiva, os respondentes recorrem primeiro a capital de terceiros, em segundo a capital próprio e, por fim, emitem ações, confirmando que a lógica do trade-off se sobrepõe a da pecking-order, em compasso 
com o estudo de Fama e French (2002) e contrariando os estudos de Myers (1984) e Myers e Majluf (1984).

De acordo com os respondentes, as empresas usam tanto o custo de capital quanto o fluxo de caixa para a avaliação de um projeto. Estas escolhem tomar dívidas de longo prazo para evitar refinanciamento em períodos difíceis, mas preferem não se endividar quando os lucros acumulados são substanciais. O objetivo principal das empresas quando emitem dívida conversível ou ações, é gerar recursos financeiros, mas as empresas preferem as dívidas conversíveis, pois essas são menos onerosas, evitam a diluição do patrimônio em curto prazo e possuem maior facilidade para resgate. Mas se optarem por emitir ações, o fazem prioritariamente para diluir o poder acionário de determinados acionistas.

Estes resultados revelam diferenças significativas se comparado ao estudo seminal de Graham e Harvey (2001), evidenciando idiossincrasias entre o Brasil e os EUA. Primeiramente, foi verificado que a técnica de orçamento de capital mais utilizada no Brasil (i.e. Opções Reais) é uma das menos utilizadas nos EUA, bem como a técnica menos utilizada no Brasil (i.e. Payback) é uma das técnicas mais utilizadas nos EUA. Adicionalmente a este, foi verificado outra diferença entre os principais fatores que os executivos brasileiros levam em conta para ajustar a taxa de desconto ou os fluxos de caixa. Enquanto no Brasil o principal fator é o "momentum", nos EUA este tem uma importância baixa de apenas $11,1 \%$ sendo seu principal fator o risco de mercado (beta). Por fim, também foi verificado uma diferença significativa entre os fatores que afetam como as firmas escolhem o montante apropriado de endividamento, no qual no Brasil o fator que menos impactou foi o rating de crédito, enquanto nos EUA este é um dos principais fatores Uma possível justificativa à isso é a orientação à bancos que o Brasil possui comparativamente a orientação a mercado nos EUA, o que, por consequência, as firmas norte-americanas acessam mais títulos de mercado, tornando o rating de crédito mais preponderante.

Com base nestes resultados o presente estudo traz contribuições teóricas e práticas para a área de finanças. Assim como em Graham e Harvey (2001) esperamos que o presente estudo contribua para novas pesquisas bem como nortear os executivos financeiros quando a usualidade de teorias e ferramentas financeiras. Espera-se também que os profissionais aprendam com o presente estudo observando como outras firmas operam. Por fim, o presente estudo buscou contribuir com aproximação entre o campo teórico de finanças ao campo prático, verificando qual teoria tem maior usualidade pelos executivos financeiros brasileiros.

\section{REFERÊNCIAS}

ABDEL-KADER, M.; LUTHER, R. Management accounting practices in the British food and drinks Industry. British Food Journal, v. 108, n. 5, p. 336-357, 2006.

ARNOLD, G. C.; HATZOPOULOS, P. D. The Theory-Practice Gap in Capital

Budgeting: Evidence from the United Kingdom. Journal of Business Finance \& Accounting, v. 27, n. 5-6, p. 603-626, 2000. 
BENETTI, C. Políticas financeiras: Estudo de propriedades métricas do Duke Special Survey On Corporate Policy no Brasil. UNISINOS - Programa de Pós-Graduação em Ciências Contábeis - Nível Mestrado. São Leopoldo, 2005

BENNOUNA, K.; MEREDITH, G. G.; MARCHANT, T. Improved capital budgeting decision making: evidence from canada. Management Decision, v. 48, n. 2, p. 225-247, 2010.

BLOCK, S. Divisional cost of capital: A study of its use by major U.S. Firms. The engineering economist, v. 48 n. 4, p. 345-362, 2003.

BRAGA, R. (2008). Fundamentos e técnicas de administração financeira. São Paulo, $1^{\circ}$ ed.

BRAU, J. C.; FAWCETT, S. E. Initial public offerings: an analysis of theory and practice. The Journal of Finance, v. 61, n. 10, p. 399-436, 2006.

BRIJLAL, P.; QUESADA, L. The Use Of Capital Budgeting Techniques In Businesses: A Perspective From The Western Cape. The Journal of Applied Business Research, v. 25, n. 4, p. 37-46, 2009.

BROUNEN, D.; JONG, A.; KOEDIJK, K. Corporate finance in europe confronting theory with practice. Journal of Economic Literature (JEL), v. 33, n. 4, p. 71-101, 2004.

CHAZI, A.; TERRA, P. R. S.; ZANELLA, F. C. Theory versus practice: perspectives of Middle Eastern financial managers. European Business Review, v. 22, n. 2, p. 195-221, 2010.

FAMA, E.; FRENCH, K. Testing Tradeoff and Pecking Order Predictions About Dividends and Debt. Review of Financial Studies, v. 15, n. 1, p. 1-33, 2002.

FILLOL, A.; FELIU, V.; LUNKES, R.; DA ROSA, F. Práticas de orçamento de capital: um estudo comparativo entre porto do Brasil e Espanha. In: VIII Congresso Ibero-americano de Administração Empresarial e Contabilidade, Espanha, 2010.

GARMAISE, M. J. Borrower Misreporting and Loan Performance. The Journal of Finance, v. 70, n. 1, p. 449-484, 2015.

GRAHAM, J. R.; HARVEY, C. R. The theory and practice of corporate finance: evidence from the field. Journal of Financial Economics, v. 60, n. 2-3, p. 187-243, 2001.

HAIR JR., J. F.; BABIN, B. J.; MONEY, A. H.; SAMOUEL, P. Fundamentos de métodos de pesquisa em administração. Porto Alegre: Bookman, 2005.

HAIR JR., J. F.; BLACK, W. C.; BABIN, B. J.; ANDERSON, R. E.; TATHAM, R. L. Análise Multivariada de Dados. 6. Ed. Porto Alegre: Bookman, 2009.

HALL, J.; MILLARD, S. Capital Budgeting Practices Used By Selected Listed South African Firms. South African Journal of Economic and Management Sciences, v. 13, n.1, p. 85-97, 2010.

HERMES, N.; SMID, P.; YAO, L. Capital Budgeting Practices: a Comparative Study Of The Netherlands And China. International Business Review, v. 16 n. 5, p. 630-654, 2007.

HOLMÉN, M.; PRAMBORG, B. Capital Budgeting And Political Risk: Empirical Evidence. Journal of International Financial Management and Accounting, v. 20, n. 2, p. 105-134, 2009.

LAZARIDIS, I.T. Capital Budgeting Practices: A Survey In The Firms In Cyprus. Journal of Small Business Management, v. 42, n. 4, p. 427-433, 2004.

LIBBY, T. R.; LINDSAY, M. Beyond Budgeting Or Budgeting Reconsidered? A Survey Of North-american Budgeting Practice. Management Accounting Research, v. 21, n. 1, p. 56-75, 2010.

LOEWENSTEIN, M.; WILLARD, G. A. (2006). The Limits Of Investor Behavior. The Journal of Finance, v. 61, n. 1, p. 231-258, 2006. 
MAlHOtRA, N. (2006). Pesquisa de Marketing: uma Orientação Aplicada. 4 Ed. Porto Alegre: Bookman.

MYERS, S. C. The Capital Structure Puzzle. The Journal of Finance, v. 39, n. 3, p. 575-592, 1984.

MYERS, S. C.; MAJLUF, N. Corporate Financing And Investment Decision When Firms Have Information That Investors Do Not Have. Journal of Financial Economics, v. 13, n. 2, p. 187-222, 1984.

NETTO, R. B. Determinantes da Estrutura de Capital de Companhias Abertas Brasileiras não-financeiras: um estudo empírico com dados em painel. Dissertação De Mestrado, Ufrn / Biblioteca Setorial Do Ccsa, 2009

OLIVEIRA, D. F.; ROCHA, F. D.; LACERDA, T. S.; SILVEIRA, VICTOR N. S. Estratégias De Financiamento Do Capital De Giro Em Empresas Do Setor Alimentício. Gepros, n. 2., 19-30, 2006.

PESTANA, M. H.; GAGEIRO, J. N. Análise de Dados para Ciências Sociais: A Complementariedade do Spss. 3. Ed. Lisboa: Sílabo.gima, 2003.

RYAN, P. A.; RYAN, G. P. Capital Budgeting Practices of the Fortune 1000: How Have Things Changed?. The Journal of Business and Management, v. 8, n. 4, p. 355-364, 2016.

SIVABALAN, P.; BOOTH, P.; MALMI, T.; BROWN, D. A. An Exploratory Study Of Operational Reasons To Budget. Accounting and Finance, v. 49, n. 4, p. 849-871, 2009.

SOUZA, P. \& LUNKES, R. J. Práticas de Orçamento de Capital: Um Estudo Em Empresas Hoteleiras De Florianópolis (Sc). Revista Universo Contábil, v. 9, n. 1, p. 28-45, 2010.

STAUB, I. D.; MARTINS, H. C.; RODRIGUES, SUZANA B. Governança Corporativa e Criação de Valor para o acionista: da Teoria à Prática, os impactos organizacionais e financeiros. Economia \& Gestão, v. 2, n. 3, p. 36-55, 2002.

VERBEETEN, F. H. M. Do Organizations Adopt Sophisticated Capital Budgeting

Practices to Deal with uncertainty in the investment decision? A Research Note. Management Accounting Research, v. 17, n. 1, p. 106-120, 2006.

Submetido em: 10-5-2019

Aceito em: 22-12-2020 